\section{An explanatory-sequential approach on PERMA and resilience among students of local colleges in the province of Batangas}

\author{
Platon, Jessica $\<$ \\ Laguna College of Business and Arts, Philippines (jecaplatonprime@gmail.com)
}

Received: 24 July 2021

Available Online: 30 July 2021

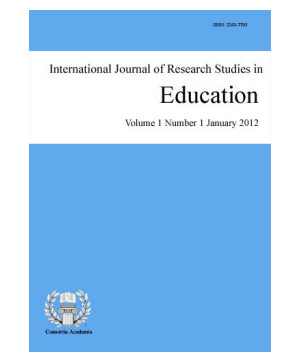

ISSN: 2243-7703 Online ISSN: 2243-7711

OPEN ACCESS

\title{
Abstract
}

The main purpose of this study was to determine the level of well-being in terms of PERMA (Positive Emotion, Engagement, Relationship, Meaning, and Accomplishment) and resilience level among students during the pandemic in both quantitative and qualitative aspect. Local Colleges in the province of Batangas were the locale of the study. The PERMA Profiler, Brief Resilience Scale (BRS), and interview questionnaire guide were used in data collection. Statistical tools and interpretative phenomenological analysis were used to analyze the data collected. Findings revealed that students' level of well-being in terms of PERMA were all in Normal Functioning and students' resilience was also at a Normal level. It was also found out that there was a significant relationship between the level of well-being and resilience level of students. In terms of qualitative aspect, the superordinate themes that emerged were Mixed of Positive and Negative Emotions, Varied Activities during the Pandemic, Student's Support System, Students' Realizations of Life during the Pandemic, Students' Accomplishments during the Pandemic, and Students' Resilience and their Coping Strategies. In conclusion, students' level of well-being was all in normal functioning and their resilience level is Normal because of the following reasons: students' have positive emotions, they were able to seize every opportunity to engage themselves in different things, they have a strong support system, they were able to lead a purposeful and meaning life and they have a sense of accomplishment. As an output of the study, a mental health program anchored in the PERMA model was proposed.

Keywords: explanatory-sequential, PERMA, resilience, local colleges 


\section{An explanatory-sequential approach on PERMA and resilience among students of local colleges in the province of Batangas}

\section{Introduction}

Since March 2020, the Philippines has been battling the pandemic. It has hit the world and society hard. The lives of people, including the lives of young people are drastically changing. The implementation of different community quarantine guidelines significantly and abruptly altered people's routine activities. The paradigm shift in teaching and learning in which the utilization and adoption of distance learning at all education levels were spurred by the pandemic. Socialization is highly discouraged and restricted. Overwhelming changes brought about by these circumstances are indeed tough and detrimental for Filipinos' social, physical and mental well-being. Transitioning to the new normal and enduring the setbacks caused too much uncertainty, fear, emotional distress, and anxiety for many, especially the learners who are directly affected. Uy (2020) mentioned that adapting to new realities and the huge change in the daily routine of adapting to the "new normal" affects the mental health of every Filipino in general.

Given the toll on students' mental health and well-being that the pandemic has brought upon, Guidance Counselors and teachers need to help students look after their mental well-being and to provide support and guidance for students to thrive for continuous holistic development despite the pandemic. Their tough job made even tougher because of the current situation, however, Guidance Counselors' role according to Nelson, Tarabochia, and Koltz (2015) is to design, deliver, and evaluate comprehensive counseling programs that are focused on enhancing student development and success. King-White (2019) stated that school counselors are the leaders, advocates, and change agents within schools that have the qualities for supporting students with mental health challenges within the school setting. Therefore, maintaining and strengthening students' well-being is in the hands of the counselors with the assistance of the teachers. Similarly, as mentioned by Spencer (2019), part of the educators' duty is ensuring students are safe and are sufficiently educated on how to support and look after their well-being. Booth (2019) stated that teachers are in the fortunate position of spending a lot of time with the students, gaining a unique insight into students' behavior outside the home. This therefore allows the teachers to act as the first line of support in times of difficulty. Also, teachers can support students' well-being by creating and fostering a safe and positive learning environment. Lastly, collaborative efforts between counselors and teachers lead to maximizing their impact on students' well-being. Therefore, teacher-counselor partnership is essential for promoting students' well-being, development and success.

The main purpose of this study is to determine students' level of well-being and resilience level during the COVID-19 pandemic in both quantitative and qualitative aspect. With all these challenges that are detrimental to our Filipino learners, they need to develop self-awareness and self-understanding when it comes to their mental well-being. Awareness of what keeps them sane and mentally healthy is an important factor not only in coping with distressing situations but also, in thriving to live a flourishing and meaningful life. This study aims to contextualize and materialize relevant mental health programs that will promote, enhance, and strengthen students' well-being and resilience.

\subsection{Theoretical Framework}

Seligman (2011) hypothesized that PERMA (Positive Emotion, Engagement, Relationships, Meaning, and Accomplishment) are the elements of well-being (Martin Seligman, 2018). According to Pascha (2020), Seligman developed a five core element of psychological well-being and happiness. Seligman believes that these five elements can help people work towards a life of fulfillment, happiness, and meaning. Seligman's theoretical model (PERMA) helps us understand these elements and what we can do to maximize each element to reach a life full of happiness. In addition, as mentioned by Kashdan (2017), Seligman argues that each of these five

50 Consortia Academia Publishing (A partner of Network of Professional Researchers and Educators) 
components is intrinsically rewarding, representing a valuable end game for any human activity. Together, these five indicators of well-being supposedly give rise to human flourishing. Maximum well-being leads to a state of flourishing. According to David (2020), flourishing is described as a state of thriving of being full of vitality, and prosper as individuals and as a group. Moreover, according to Moore (2020), resilience theory argues that it's not the nature of adversity that is most important, but how we deal with it. This explains that when we face adversity, misfortune, or frustration, resilience helps us bounce back, survive, recover, and even thrive.

\subsection{Research Design}

The study utilized mixed methods research design. Specifically, it employed sequential explanatory approach. Mixed methods research is the combination and integration of qualitative and quantitative methods in the same study. As cited in Azorin (2016), the overall purpose and central premise of mixed methods studies are that the use of quantitative and qualitative approaches in combination provides a better understanding of research problems and complex phenomena than either approach alone (Creswell \& Plano Clark, 2007). Through this approach, students' level of well-being and resilience level in both quantitative and qualitative aspect were determined.

\subsection{Research Paradigm}

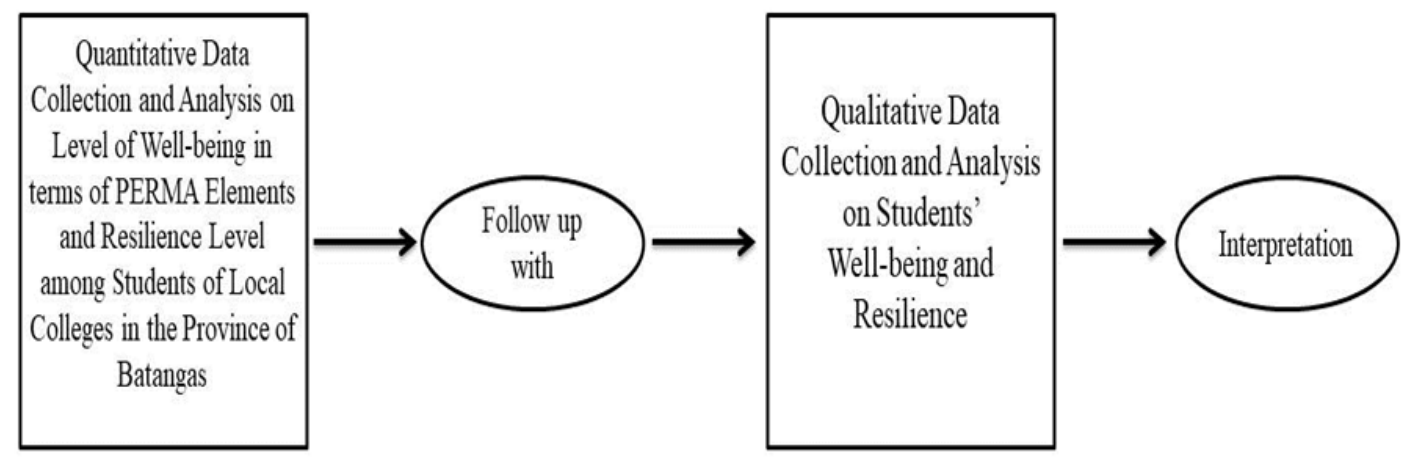

Figure 1. Research Paradigm

Purpose Statement - The main purpose of this study was to determine the level of well-being in terms of PERMA elements and resilience level among students of Local Colleges in the Province of Batangas during the COVID-19 pandemic in both quantitative and qualitative aspect. Determine the resilience level among students of Local Colleges in the Province of Batangas during the COVID-19 pandemic in both quantitative and qualitative aspect. In addition, this study also sought to determine if there is any significant relationship between the level of well-being and resilience level among students. Lastly, based on the findings of the study, a mental health program anchored in PERMA model was sought to propose.

Hypothesis - This study hypothesized that there is no significant relationship between the level of well-being and resilience level among students of Local Colleges in the Province of Batangas during the COVID-19 pandemic.

Scope and Delimitations - The main purpose of the study was to determine the students' level of well-being and resilience level during the COVID-19 pandemic. Well-being and resilience were determined using the mixed methods research design. Well-being was measured in terms of PERMA elements: positive emotion, engagement, relationships, meaning, and accomplishment. Level of well-being and resilience level were measured through the use of two standardized tools - The PERMA Profiler and Brief Resilience Scale. Meanwhile, Focus Group Discussion was conducted to qualitatively determine the well-being and resilience of the students. Respondents of the study were the tertiary students aging from 18 to 22 years old from different programs and levels of Local Colleges in the Province of Batangas. Schools particularly Colegio ng Lungsod ng Batangas (CLB), Kolehiyo ng Lungsod ng Lipa (KLL), and Tanauan City College (TCC) were the research locale of the study. 
The method of data collection used was an internet-based data gathering procedure through Google Form. Aside from the current situation brought about by the pandemic where face-to-face interaction is discouraged and restricted especially in the educational institutions, the two instruments were only possible to administer through an online platform, hence, paper-and pencil administration was not possible. Focus group discussion (FGD) was also conducted online through Google Meet.

\section{Related Literature and Studies}

Mulder (2018) and Pascha (2020) both mentioned that the PERMA model was developed by one of the founders of positive psychology, Martin Seligman. This model helps people to work towards a life of fulfillment, happiness, and meaning. PERMA is the acronym for the five - according to Seligman - important building blocks of well-being and happiness: Positive emotion, Engagement, Relationship, Meaning, and Accomplishment. There are numerous definitions given to resilience. Resilience is defined by many as either a trait or a process. Cohen (2016) and Hurley (2019) defined resilience as a trait. They both stated that resilience is the capacity or ability of a person to adapt, cope and recover from difficult life events and to new situations. However, American Psychological Association (APA), Fernández et al. (2018), and Riopel (2020) all defined resilience as a process. Uniformly, they defined resilience as the process of successfully adapting well in the face of adversity and bouncing back quickly especially through mental, emotional, and behavioral flexibility and adjustment to external and internal demands.

Some factors contribute to building and/or strengthening one's resilience. According to American Psychological Association (APA), several factors contribute to how well people adapt to adversities, predominant among them (a) the ways in which individuals view and engage with the world, (b) the availability and quality of social resources, and (c) specific coping strategies. On the other hand, as mentioned by Hurley (2019), there are protective factors such as social support, realistic planning, self-esteem, coping skills, communication skills, and emotional regulation that help build resilience by improving coping skills and adaptability. Moreover, Harms et al. (2018) mentioned three protective factors: individual factors, social factors, and community factors.

Well-being and resilience are important in preventing the onset of mental health problems as well as potentially lessening the severity of existing mental health problems. There are a number of studies that provide evidence about the relationship between well-being and resilience. Abreu and Blanco (2017), Chow et al. (2018), Fernández et al. (2018), Harms et al. (2018), Kajbafnezhad and Keshi (2015), Li and Hasson (2020), Satici (2016), Svence and Majors (2015), Tomyn and Weinberg (2016), Turner et al. (2017), Wu et al. (2020), and Yu and Chae (2020) all stated that psychological well-being and resilience have positive and significant correlation and relationship. Resilience significantly predicts and influences well-being, therefore, it is one of the psychological factors that affect well-being. Moreover, Burns et al. (2020), Khan et al. (2020), The New York Times (2020), and Anderson (2020) all presented that this pandemic had a significant impact on student's mental health and well-being. Comparably, Camitan, and Bajin (2021) found out that all the five pillars of well-being are significant positive correlates of resiliency. They also believed that the result of their study found clear support to PERMA concept of Seligman (2011) as necessary ingredients of resiliency. In a nutshell, resilience and well-being are fundamentally related.

\section{Methodology}

The study utilized mixed methods research design. Specifically, it employed sequential explanatory approach. Mixed methods research is the combination and integration of qualitative and quantitative methods in the same study. As cited in Azorin (2016), the overall purpose and central premise of mixed methods studies are that the use of quantitative and qualitative approaches in combination provides a better understanding of research problems and complex phenomena than either approach alone (Creswell \& Plano Clark, 2007). Through this approach, students' level of well-being and resilience level in both quantitative and qualitative aspect were 
determined.

The instruments used in this study were The PERMA Profiler, Brief Resilience Scale (BRS), and Interview questionnaire guide. The PERMA Profiler is a standardized measure developed by Butler and Kern (2015). This tool was used to measure the level of well-being of the students. This instrument measured flourishing in terms of five domains: positive emotion, engagement, relationships, meaning, and accomplishment. This measure consisted of 23 items wherein the health, negative emotion, loneliness, and overall happiness questions act as filler questions and provide more information; there were 15 PERMA questions (3 per PERMA domain). Questions were on an 11-point scale ranging from 0 to 10 , with the endpoints labeled. The scores were calculated based on the average of the items comprising each factor and were interpreted as very high functioning, high functioning, normal functioning, sub-optimal functioning, and languishing. Moreover, the Brief Resilience Scale (BRS) is a standardized measure developed by Smith et al. (2008). This tool was used to measure the resilience level. BRS was created to assess the ability to bounce back or recover from stress. It is a simple, self-assessment tool that individuals can use to assess their resilience. As cited in Psytoolkit.org, according to Windle et al. (2011), it is one of the best and highly recommended resilience scales. This measure is consisting of six statements for individuals to agree or disagree. Item responses can strongly disagree, disagree, neutral, agree, or strongly agree. Scoring was measured on a 5-point scale and can generate a resilience score ranges from 6-30. Scores were interpreted as high resilience, normal resilience, and low resilience.

The researcher first conducted quantitative data collection. The researcher sent a request letter to the College President or Administrator of the three local colleges. Letters were sent through email. After getting her permission, the researcher requested the total number of students aging from 18-22 years old. Data obtained was used to compute the sample size. The researcher then coordinated with the assigned personnel of the institutions to assist her in the dissemination of the research instruments. Research instruments were in the Google Form version. A letter regarding the nature and objectives of the study as well as the letter of consent were also included in Google Form. Upon meeting the target number of respondents, the researcher gathered and organized the responses from the Google Sheet. Data obtained were arranged using Excel and presented per element. Afterward, consolidated data were forwarded to the Statistician for computation. Statistical tools such as frequency distribution, weighted mean, and Pearson's Correlation Coefficient were used.

Afterward, the researcher then conducted qualitative data collection. The interview questionnaire guide used was validated by three Qualitative Data Analyst (QDA) and one potential participant of the study. On the other hand, the researcher selected ten (10) students from the respondents of the study. They were chosen to participate in the Focus Group Discussion. The researcher sent a letter of informed consent to the participants. They were also informed about the details of the Focus Group Discussion to be conducted. After Focus Group Discussion was conducted through Google Meet, responses were collected and transcribed. After careful analysis of the responses from the ten (10) participants particularly zeroing in on the similarities of the responses, superordinate and subordinate themes were extracted and presented in thematic charts. Responses were analyzed using interpretative phenomenological analysis or thematic analysis. The researcher then forwarded the thematic charts to the assigned Qualitative Data Analyst to check and verify the accuracy of the themes that emerged. Both quantitative and qualitative results were compared, contrasted, and interpreted. Findings from the qualitative data were used to further explain and elaborate on the quantitative results.

\section{Results and Discussions}

Based on the data gathered and after cautious and comprehensive analysis of the investigation, the following are the findings of the study in summarized form. The following tables provided the results of the assessments conducted to determine the level of well-being among students of Local Colleges in the Province of Batanags during the COVID-19 pandemic in terms of Positive Emotion, Engagement, Relationship, Meaning, and Accomplishment. 


\section{Table 1.1}

Well-being among Students in Batangas during the COVID-19 pandemic in terms of Positive Emotion

\begin{tabular}{|c|c|c|c|}
\hline Indicators & & Mean & Interpretation \\
\hline P1: In general, how often do you feel joyful? & & 6.91 & $\mathrm{NF}$ \\
\hline P2: How often do you feel positive? & & 7.14 & NF \\
\hline P3: To what extent do you feel contented? & & 7.94 & NF \\
\hline & Composite & 7.33 & $\mathrm{NF}$ \\
\hline
\end{tabular}

Legend: 9 and above Very High Functioning (VHF), 8 to 8.9 High Functioning (HF) 6.5 to 7.9, Normal Functioning (NF), 5 to 6.4 Sub Optimal Functioning (SF), and below 5 Languishing (L).

Table 1.1 shows the level of well-being among students of local colleges in the Province of Batangas during the COVID-19 pandemic in terms of Positive Emotion. The general composite assessment is $\mathbf{7 . 3 3}$ and interpreted as Normal Functioning. It implies that the student's level of well-being is in normal functioning because of the positive emotions they have despite the pandemic. Due to the circumstances brought by the pandemic, chances are, students experienced a roller coaster of emotions which includes but not limited to being happy, sad, excited, angry, afraid, grateful, proud, scared, confused, stressed, relaxed, worried, bored, frustrated, tired, and anxious. Students being contented could mean that they let their positive emotions outnumber negative ones. Students would probably rather feel a positive emotion than a negative one. However, although positive emotions are present, being joyful is not the emotion they always feel.

Balibay (2020) mentioned that Filipinos are finding more reasons to be positive in this time of lockdown to stop the spread of COVID-19. Also, Garcia (2018) stated that even if in the midst of poverty, politics, and calamities, Filipinos seem to always see the silver lining. As cited in Eliüşük (2018), according to Seligman (2011), we need a positive feeling in our lives to live well. Likewise, as cited in Pogosyan (2016), our day-to-day positive emotions function as nutrients for our overall well-being, that today's positive emotions do not simply exemplify today's well-being, they also help to create next month's increase in well-being. As cited in Ford and Mauss (2020), research has shown that people who experience more frequent positive emotions and less frequent negative emotions have higher well-being. Research has shown that focusing on positive emotions has a range of benefits such as broadened ideas or activities, improved performance-related outcomes, improved general well-being, decreased feelings of stress, and reduced negative emotions.

Comparably, on the qualitative aspect on students' level of well-being in terms of positive emotion, a theme of Mixed of Positive and Negative Emotions was derived from the students' responses. Looking at the responses of the participants, it can be concluded that participants both experienced positive emotions such as being happy and optimistic and negative emotions which include loneliness, fear, feeling of isolation, and uncertainty. The participants reported being happy because this pandemic brought their family together which somehow built a strong relationship and connection among them. Also, participants discovered that there were a variety of things that they can enjoy while staying at home. On the other hand, the uncertainty, the restrictions and limitations, the challenges of online learning, and the health risk imposed by the pandemic are some of the reasons for the negative emotions felt by the participants.

\section{Table 1.2}

Well-being among Students in Batangas during the COVID-19 pandemic in terms of Engagement

\begin{tabular}{|c|c|c|}
\hline Indicators & Mean & Interpretation \\
\hline E1: How often do you become absorbed in what you are doing? & 6.88 & NF \\
\hline E2: To what extent do you feel excited and interested in things? & 7.50 & NF \\
\hline E3: How often do you lose track of time while doing something you enjoy? & 6.54 & NF \\
\hline Composite & 6.97 & NF \\
\hline
\end{tabular}

Legend: 9 and above Very High Functioning (VHF), 8 to 8.9 High Functioning (HF), 6.5 to 7.9 Normal Functioning (NF), 5 to 6.4 Sub Optimal Functioning (SF), and below 5 Languishing (L).

Table 1.2 showed the level of well-being among students of local colleges in the Province of Batangas during the COVID-19 pandemic in terms of Engagement. The general composite assessment is 6.97 and interpreted as Normal Functioning. The results connoted that because students engaged themselves in different things and activities, their level of well-being is in normal functioning. Although it may seem like a

54 Consortia Academia Publishing (A partner of Network of Professional Researchers and Educators) 
tough time when students can't go out freely and enjoy whatever outdoor activities they want, this pandemic opens every opportunity for them and what matters is how they use them. Despite no ostensible end in sight, during this pandemic, everybody has time to do exciting and interesting things they usually don't have time to do. It means that they still enjoy and spend their free time doing a variety of things. Since students have more time for themselves, it enables them to learn more things and developed some new interests to keep themselves busy and energized. It is the best time to make use of the internet to play online games, watch TV series and movies, do creative things, and shop online. There are also things they enjoy doing together with their family members. However, students may also get bored doing them for a long time and tend to jump from one thing to another. Since there are a lot of things to try, they may get absorbed once or twice but not all the time.

As stated by Pascha (2020), activities that meet our need for engagement flood the body with positive neurotransmitters and hormones that elevate one's sense of well-being. This engagement helps us remain present as well as synthesize the activities where we can find calm, focus, and joy.

Comparably, on the qualitative aspect on students' level of well-being in terms of engagement, a superordinate theme, Varied Activities during the Pandemic was derived from the responses of the participants. The subordinate themes that emerged from the responses were: Playing Online Games (Mobile Legends); Watching TV/Drama Series; Engaging in Church-related Activities; Online Shopping; Creating and Watching TikTok Videos; Enhancing Skills, and Completing Academic Requirements.

The participants enjoyed a variety of activities that keep them sane during the pandemic. The activities they have were mostly indoor activities because outdoor activities were restricted. Also, it can be noted that physical interaction with others is not that required in doing such activities. Some of the participants openly admitted that things such as creating and watching Tiktok videos, shopping online in Lazada, Shoppee, and even Food Panda, are their stress relievers. People need something to enjoy no matter what. People do have their own saving grace to withstand all difficult circumstances. From the responses of the participants, the activities could be one of the saving grace of the participants. To not get drawn by the circumstances, activities that will divert one's focus are necessary. Not all people are indeed alike. Different people have different interests. One can enjoy doing these things while one does not. In these trying times, because physical socialization and interaction are limited, it is not surprising that most people enjoyed activities that involve technology.

\section{Table 1.3}

Well-being among Students in Batangas during the COVID-19 pandemic in terms of Relationship

\begin{tabular}{lcc}
\hline \multicolumn{1}{c}{ Indicators } & Mean & Interpretation \\
\hline R1: To what extent do you receive help and support from others when you need it? & 7.33 & NF \\
R2: How satisfied are you with your personal relationships? & 7.72 & NF \\
R3: To what extent do you feel loved? & 7.83 & NF \\
\end{tabular}

Legend: 9 and above Very High Functioning (VHF), 8 to 8.9 High Functioning (HF), 6.5 to 7.9 Normal Functioning (NF), 5 to 6.4 Sub Optimal Functioning (SF), and below 5 Languishing (L).

Table 1.3 showed the level of well-being among students of local colleges in the Province of Batangas during the COVID-19 pandemic in terms of Relationship. The general composite assessment is $\mathbf{7 . 6 3}$ and interpreted as Normal Functioning. The results signify that the support system plays an important role in students' well-being during the pandemic. Having a strong support system helps their well-being to be in normal functioning. Students as they battle with an onslaught of stressors caused by the pandemic rely on their family, friends, workmates, romantic partners, confidants, and companions to ease the weight of the circumstances they are experiencing. Being stuck with their family members opens opportunities to express and to receive love. The support they are receiving from those who play a supportive role to them is probably one of the reasons why they feel loved. However, students may feel and think that they do not always need help because they can manage well their circumstances. Some students are independent hence they can stand on their own.

Pascha (2020) stated that relationships and social connections are crucial to a meaningful life. She added 
that positive relationships with one's parents, siblings, peers, coworkers, and friends are a key ingredient to overall joy. Likewise, as cited in Eliüşük (2018), according to Butler and Kern (2016), as humans we are "social beings" and good relationships form the essence of our well-being. People who have meaningful and positive relationships with others are happier than those who do not have. Forgeard et al. (2011) claimed that relationships are important because people want to be loved and appreciated. Similarly, Tay et al. (2012) stated that social relationships have positive effects on health and individuals' well-being.

Comparably, on the qualitative aspect on students' level of well-being in terms of relationship, a superordinate theme, Student's Support System was derived from the responses of the participants. The subordinate themes that emerged from the responses were: Financial Support from Family; Emotional Support from Friends, Spiritual Support from Church mates.

Analyzing the responses of the participants, it can be noted that their family is their number one support system. It was followed by their friends and other acquaintances. The participants mentioned that the support their family provides for them is usually financial and emotional. They are like their backup whenever they struggle. One participant even mentioned that her grandfather is even willing to give them food he is about to put in his mouth. This statement is the participant's testimony of how supportive her grandfather is. Participants also get support from their friends who are one of the sources of encouragement. Even the situation does not permit them to occasionally meet, social media is one way to communicate.

Having a support system is important in people's life. Family members are the ones you can always run to whenever you need help. No matter how hard things are, they will never leave your side. Family is the number one supporter because they are matchless, they are your home. Since they see how you struggle, they will help you get through with it. Any type of support anyone can get from their loved ones are significant and helpful. On the other hand, besides family members, friends are always there to be the shoulder to lean on. Through thick and thin, up and down, some friends will always be around to support you. They are the friends who also become your family. Support from these groups of people is what we need during these difficult times.

\section{Table 1.4}

Well-being among Students in Batangas during the COVID-19 pandemic in terms of Meaning

\begin{tabular}{|c|c|c|}
\hline Indicators & Mean & Interpretation \\
\hline M1: To what extent do you lead a purposeful and meaningful life? & 7.69 & NF \\
\hline M2: To what extent do you feel that what you do in your life is valuable and worthwhile? & 7.78 & NF \\
\hline M3: To what extent do you feel you have a sense of direction in your life? & 7.58 & NF \\
\hline Composite & 7.68 & NF \\
\hline
\end{tabular}

Legend: 9 and above Very High Functioning (VHF), 8 to 8.9 High Functioning (HF), 6.5 to 7.9 Normal Functioning (NF), 5 to 6.4 Sub Optimal Functioning (SF), and below 5 Languishing (L).

Table 1.4 shows the level of well-being among students of local colleges in the Province of Batangas during the COVID-19 pandemic in terms of Meaning. The general composite assessment is $\mathbf{7 . 6 8}$ and interpreted as Normal Functioning. The results indicated that despite all of these, students were able to lead a purposeful and meaningful life, have a sense of direction, and treasure their life as valuable and worthwhile. They still manage to function well with their life's purpose and meaning being intact. Because of the limitations and restrictions, little things students do all of a sudden become important and worthy. Students have to make sense of what has happened and with all their might find additional meaning in their lives. On the other hand, because of the uncertainty this situation brings, there may be a point in their lives that their goals and aspirations shattered. Lost and confused on which path to take and what decisions to make. Nevertheless, their shattered goals can be fixed once they give themselves a chance to re-evaluate their goals and re-discover their life's purpose and meaning. It is like crafting their life once again.

As cited in Ascenso et al. (2018), meaning provides a sense that one's life matters. Belyh (2019) also agreed that we have to have a "meaning of life" to be happier. Something that keeps us going and that having a meaning just makes life in general easier. Moreover, Alandete (2015) found out that meaning in life and psychological 
well-being is positively and significantly associated variables which indicate that the more experience of life, the greater psychological well-being. Comparably, as cited in Krok (2017), research on different facets of psychological well-being shows that meaning in life is associated with more optimal human functioning and health benefits (Ryff \& Singer, 2008), achievement striving (Steger et al., 2008), and global happiness (Ryff \& Keyes, 1995).

Comparably, on the qualitative aspect on students' level of well-being in terms of meaning, a superordinate theme, Students' Realizations of Life during the Pandemic was derived from the responses of the participants. The subordinate themes that emerged from the responses were: Clear Life Vision; "Life is Short", and Perseverance against Life's Challenges. The responses of the participants implied that because of the pandemic, there are realizations from what they have experienced. Realizations in their life's direction, life's meaning, and purpose. Some participants were once carefree, easygoing, and happy-go-lucky with their life. However, because of what they have experienced during the pandemic, they seemed to be enlightened that their objective and sense of direction should be clear to them. The reality hit them that life is short. Participants mentioning that anytime your life could end, that you only live once so should live your life to the fullest, and that one should do whatever makes them happy because life is short so they should enjoy it are the shreds of evidence of their realization. Moreover, participants also realized that in these trying times, being steadfast is what they need. Because of this, they will not consider circumstances as hindrances to achieve their goals.

\section{Table 1.5}

Well-being among students in Batangas during the COVID-19 pandemic in terms of Accomplishment

\begin{tabular}{|c|c|c|}
\hline Indicators & Mean & Interpretation \\
\hline $\begin{array}{l}\text { A1: How much of the time do you feel you are making progress towards accomplishing your } \\
\text { goals? }\end{array}$ & 7.02 & $\mathrm{NF}$ \\
\hline A2: How often do you achieve the important goals you have set for yourself? & 7.43 & NF \\
\hline A3: How often are you able to handle your responsibilities? & 7.48 & $\mathrm{NF}$ \\
\hline$e^{2}$ & 7.31 & NF \\
\hline
\end{tabular}

Table 1.5 showed the level of well-being among students of local colleges in the Province of Batangas during the COVID-19 pandemic in terms of Accomplishment. The general composite assessment is 7.31 and interpreted as Normal Functioning. The results indicated that students having a sense of accomplishment is a big help to their well-being. The progress they have made, the responsibilities they handled well, and the goals they have achieved so far, fuel their eagerness to live well and happy despite the pandemic. Some of the students' responsibilities during this pandemic are to abide by the policies implemented by the authority, help and support their family, and most importantly, to study well. Them being uninfected by the virus, being happy with their family, and them excelling in their academic performance were some of the pieces of evidence that they were able to handle their responsibilities well. However, the feelings of uncertainty, confusion, and being isolated could affect the students' sense of achievement. There may be doubt within them because they are uncertain whether they are moving forward or they are stuck at the moment.

Pascha (2020) stated that having goals and ambition in life can help us to achieve things that can give us a sense of accomplishment and that having accomplishments in life is important to push ourselves to thrive and flourish. Similarly, according to Brhlik (2020), if someone reach their goals, they'll cause a sense of pride and fulfillment. Chasing and achieving feasible goals will bring up other elements of happiness. Reaching an objective will cause a sense of accomplishment, which definitely triggers positive emotions. In a study conducted by Gräbel (2017), it was found out that there is a positive relationship between emotional and psychological well-being and academic achievement.

Comparably, on the qualitative aspect on students' level of well-being in terms of accomplishment, a superordinate theme, Students' Accomplishments During the Pandemic was derived from the responses of the participants. The subordinate themes that emerged from the responses were: Positive Academic Performance; 

for the Family's Achievement.

The responses of the participants proved that this pandemic is never a hindrance to achieve something. The subordinate themes are the evidence of it. Despite the challenges in the distance and blended learning, participants still managed to have a good academic performance and maintain their names on the Dean's List. Some participants also reported that completing their academic requirements is a big accomplishment for them. Developing and enhancing skills such as learning how to cook, improving drawing skills, being able to face fear, and becoming digitally literate are some of the things participants achieved. Work-related achievements and being able to help their family were also the things that make the participants feel a sense of accomplishment.

Table 2

Resilience Level among Students of Local Colleges in the Province of Batangas during the COVID-19 pandemic

\begin{tabular}{|c|c|c|c|}
\hline Indicators & & Mean & Interpretation \\
\hline I tend to bounce back quickly after hard times. & & 3.55 & NR \\
\hline I have a hard time making it through stressful events. & & 2.55 & LR \\
\hline It does not take me long to recover from a stressful event. & & 3.29 & NR \\
\hline It is hard for me to snap back when something bad happens. & & 2.69 & LR \\
\hline I usually come through difficult time with little trouble. & & 3.27 & NR \\
\hline \multirow[t]{2}{*}{ I tend to take a long time to get over set-backs in my life. } & & 2.70 & LR \\
\hline & Composite & 3.01 & NR \\
\hline
\end{tabular}

Legend: 4.31-5.00 High Resilience (HR), 3.00-4.30 Normal Resilience (NR), and 1.00-2.99 Low Resilience (LR).

Table 2 showed the resilience level among students of local colleges in the Province of Batangas during the COVID-19 pandemic. The general composite assessment is $\mathbf{3 . 0 1}$ and interpreted as Normal Resilience. The results connoted that despite the circumstances, students still manage to become resilient. Undeniably, this time is the most uncertain time for them throughout their journey as a student. They have had to overcome significant crises in their studies, family, career, interpersonal, and even intrapersonal. They were able to withstand setbacks, challenges, frustrations, and failures. The result could mean that they have endured those unfortunate circumstances. Or if not overcome, they were able to cope and adapt well to the unprecedented times. They tend to bounce back quickly after hard times probably because of the kind of mindset they have whenever they face difficulties. Engagement activities and a large network of support systems also play an important role. Different coping strategies were also available for them to proactively utilize. Students, instead of floundering or letting things keep them down, they were able to pick themselves up from a downfall. However, there may be students who were able to bounce back quickly but there were also who weren't able to do that. It could mean that some found a pretty good way of dealing with it more quickly than others. Also, it could mean that some are experiencing a minimal amount of stress compare to other. Besides, it may be true that students were able to bounce back quickly but the process is not smooth. Because each has different perceptions about their own problems and it is a case-to-case basis. It all depends on how students look at things. Also, it depends upon the gravity of the situation the students are dealing with. There are instances that it is easy for them to bounce back but there are also times that it was hard to make it through with it.

Cohen (2020) and Hurley (2019) both defined resilience as how well a person can adapt and recover from difficult events in their life. Riopel (2020) added that it is being able to bounce back quickly in times of stress. As cited in McGillivray and Pidgeon (2015), according to DeRoseier et al. (2013), students with higher levels of psychological distress have reported lower levels of resilience. Comparably, on the qualitative aspect on students' resilience level, a superordinate theme, Students' Resilience and their Coping Strategies was derived from the responses of the participants. The subordinate themes that emerged from the responses were: Positive Emotion towards Positive Outcome; Desirable Activities; Support System; Self-Reflection; Life's Meaning and Purpose, and Accomplishments.

Based on the responses, the participants have different coping strategies to bounce back from stressful situations brought by the pandemic. Some focused on their mindset and emotion Some tried to enjoy desirable 
Explanatory-sequential approach on PERMA and resilience among students of local colleges in Batangas activities, some reached their and hands out to their support systems. Some reflected on their life's meaning and purpose. Lastly, some made their accomplishments the reason to move forward. Participants made every aspect of their life to be the reason to come through difficult times.

With all the unexpected stress and adversity this pandemic caused, being resilient is what we need to be able to withstand all of these. Resilience is a big factor for us to get through and overcome difficult circumstances. However, people tend to respond to stress and adversity differently. People used different strategies to cope with them. It depends upon the person on where he or she gets the strength to become resilient. During this pandemic, we must keep doing things that will keep us have a positive outlook in life, continuously develop realistic goals, stay connected, appreciate our wins small or big, and cultivate our life's meaning and purpose. People should maximize the sources of resilience to build, strengthen, enhance, and increase the capacity to become one.

\section{Table 3}

Significant Relationship between Well-being and Resilience among Students in Batangas during COVID-19

\begin{tabular}{|c|c|c|c|c|}
\hline & r value & $p$ value & Decision & Remarks \\
\hline Positive Emotion & $.294^{* *}$ & .000 & Reject Ho & Significant \\
\hline Engagements & $.204^{* *}$ & .000 & Reject Ho & Significant \\
\hline Relationship & $.274^{* *}$ & .000 & Reject Ho & Significant \\
\hline Meaning & $.236^{* *}$ & .000 & Reject Ho & Significant \\
\hline Accomplishment & $.242^{* *}$ & .000 & Reject Ho & Significant \\
\hline
\end{tabular}

Table 3 showed the test of the Significant Relationship Between the level of well-being and resilience level among students of local colleges in the Province of Batangas during the COVID-19 pandemic. The probability values are all less than the level of significance at .05 thus reject the null hypothesis. It can be concluded that there is a significant relationship between the level of well-being and resilience level among students of local colleges in the Province of Batangas during the COVID-19 pandemic.

The results above connoted that there is a positive or direct association between the level of well-being and resilience level of the students. This implies that the higher the level of well-being, the higher the resilience level and vice versa. It can be noted that the two variables have a reciprocal relationship. There is a significant relationship between the level of well-being in terms of the five elements and resilience level. This could mean that having a positive emotion, being engaged, having a good support system, having a meaning in life, and having a sense of accomplishment is fundamentally associated with having a higher resilience level. This also indicates that the five elements are important variables in improving students' resilience. These elements can be considered as one of the protective factors that are related to resilience.

As cited in Harms et al., (2018), resilience and well-being are fundamentally related and, in some instances, resilience is even measured using well-being instruments (Davydov et al., 2010; Windle, 2011). Some researchers have argued that higher levels of well-being serve as an antecedent of resilience (e.g. Kuntzet al. 2016). There are a number of studies that provide evidence about the relationship between well-being and resilience. Abreu and Blanco (2017), Chow et al. (2018), Fernández et al. (2018), Harms et al., (2018), Kajbafnezhad and Keshi (2015), Li \& Hasson (2020), Satici (2016), Svence and Majors (2015), Tomyn and Weinberg (2016), Turner et al. (2017), Wu et al., (2020), and Yu and Chae (2020) all stated that psychological well-being and resilience have positive and significant correlation and relationship. The results of the studies point out that resilience is an important variable in improving psychological well-being and that well-being leads to the increase of resilience and vice versa.

Relative to this, Moreover, as stated by Fernández et al. (2018), positive emotional states lead to higher levels of resilience which means that resilience is partly due to the presence of positive emotions. Comparably, as cited in $\mathrm{Wu}$ et al. (2020), resilience and positive emotions might have a reciprocal influence on each other (Smith, 2009), Tugade et al. (2005) argued that positive emotions served an important function in the ability of resilient individuals to rebound from stressful encounters. Tyler (2018) stated that resilience is a key aspect of 
engagement because it helps individuals rebound from negative events.

Furthermore, according to Lanquist (2016), research has shown that a strong support system can promote resilience and help someone manage stress during a difficult time. Similarly, Southwick et al. (2016) stated that social support is a key correlate of psychological resilience; however, its effectiveness may vary by the type of support provided and the extent to which it matches an individual's need.

Lastly, as an output of this study, a Mental Health Program utilizing the PERMA Model was made. This program will serve as a guide for the Local Colleges as it promotes students' mental health and resilience.

\section{Conclusions and Directions for Future Use}

\subsection{Conclusions}

Based on the aforementioned findings of the study, the following conclusions have been derived:

First, students' level of well-being is in normal functioning because of the positive emotions they have despite the pandemic. Although students experience a roller coaster of emotions, it could mean that they let the positive emotions outnumber negative ones. Also, because they were able to seize every opportunity to engage themselves in different things, do exciting and interesting things they usually don't have time to do, and spent their free time learning more things and developed some new interests to keep them busy and energized. The strong supports system plays an important role in students' well-being during the pandemic. Battling with an onslaught of stressors, students rely on their family, friends, workmates, romantic partner, confidants, and companions. The support they are receiving from those who play a supportive role to them plays a big part for them to withstand circumstances. Relative to this, despite all extraordinary situations that caused uncertainty and confusion, students were able to lead a purposeful and meaningful life, have a sense of direction, and treasure their life as valuable and worthwhile. They still manage to function well with their life's purpose and meaning being intact. Lastly, students having a sense of accomplishment are a big help to their well-being. The progress they have made, the responsibilities they handled well, and the goals they achieved so far, fuel their eagerness to live well and to be happy despite the pandemic.

Second, despite the circumstances, students still manage to become resilient. Having positive emotions, doing desirable activities, maximizing their support system, reflecting on themselves, having a clear vision on their life's meaning and purpose, and appreciating their accomplishments help them overcome and withstood significant crises, setbacks, challenges, frustrations, and failures. They were also able to cope and adapt well to unprecedented times.

Third, that there was a significant relationship between the level of well-being and resilience level among students of Local Colleges in the Province of Batangas. There was a positive or direct association between the level of well-being and resilience level of the students. It implied that the higher the level of well-being, the higher the resilience level and vice versa. It can be noted that the two variables have a reciprocal relationship. Having a positive emotion, being engaged, having a good support system, having meaning in life, and having a sense of accomplishment is fundamentally associated with having a higher resilience level.

Finally, the proposed mental health program is essential and is a great initiative to promote students' mental health and resilience.

\subsection{Recommendations}

The following are the recommendations offered based on the summarized findings and conclusions drawn:

First, Local Colleges may take initiatives towards guiding students to maintain and improve their well-being

60 Consortia Academia Publishing (A partner of Network of Professional Researchers and Educators) 
Explanatory-sequential approach on PERMA and resilience among students of local colleges in Batangas

using the PERMA model. Students' well-being in terms of PERMA elements were all Normal Functioning despite there are two higher levels after that. Local colleges should aim for a High Functioning or if possible Very High Functioning level of well-being. Local Colleges may also take measures to address concerns that affect students' well-being.

Second, Local Colleges may cultivate resilience more among students through meaningful programs or activities. Students' resilience level is Normal; however, Local Colleges should aim for a High resilience level of students. Students should be equipped with the capacity to adapt skillfully and cope effectively with life's adversity. Besides, Local Colleges may also take action to identify the factors contributing to low resilience.

Third, Local Colleges may opt to utilize other models or frameworks that will reinforce more the relationship of the well-being and resilience. This initiative will be a great stride to continuously and consistently be able to create and foster safe, productive, and positive learning environment. Since well-being and resilience are important factors to prevent the onset of mental health problems as well as potentially lessening the severity of existing mental health problems, Local Colleges may diligently encourage collaborative efforts among the members of the institution to maximize their impact on students' well-being and resilience.

Fourth, Local Colleges may utilize the proposed mental health program or make it tailored-made to ensure that it fits well to the characteristics of students they have. Local Colleges may also use the program as the initial basis to start formulating policies and services to further promote students' mental health.

Lastly, future researchers may utilize other well-being and resilience framework or model to assess students' well-being and resilience levels. Also, they may use this study as a reference for future research about students' well-being and resilience level during the COVID-19 pandemic or any other adversities in life.

\section{References}

Abreu, H., \& Blanco, A. (2017). The well-being at work and resilience: A study correlation in nursing technicians in hospital. Revista Psicologia, Diversidade e Saúde, 6(3), 170-180. https://doi.org/10.17267/2317-3394RPDS.V6I3.1434

García-Alandete, J. (2015). Does meaning in life predict psychological well-being? An analysis using the Spanish versions of the Purpose-in-Life Test and the Ryff's Scales. The European Journal of Counselling Psychology, 3(2), 89-98. https://doi.org/10.5964/ejcop.v3i2.27

Anderson, G. (2020, October 12). A Generation Defined by the Pandemic. Inside Higher Ed. https://www.insidehighered.com/news/2020/10/15/students-continue-be-stressed-about-college-their-fut ures

Ascenso, S., Perkins, R., \& Williamon, A. (2018). Resounding meaning: A perma wellbeing profile of classical musicians. Frontiers in Psychology, 9. https://doi.org/10.3389/fpsyg.2018.01895

Belyh, A. (2019, November 4). The perma model: Bringing well-being and happiness to your life. Cleverism. https://www.cleverism.com/perma-model-bringing-well-being-and-happiness-to-your-life/

Booth, F. (2019, November 14). A teacher's tips: Supporting student wellbeing in your classroom. Medium. https://medium.com/twinkl-educational-publishers/a-teachers-tips-supporting-student-wellbeing-in-your -classroom-9524b39296a

Butler, J., \& Kern, M. L. (2016). The PERMA-Profiler: A brief multidimensional measure of flourishing. International Journal of Wellbeing, 6(3), 1-48. https://doi.org/10.5502/ijw.v6i3.526

Burns, D., Dagnall, N., \& Holt, M. (2020). Assessing the impact of the Covid-19 pandemic on student wellbeing at universities in the United Kingdom: A conceptual analysis. Frontiers in Education, 5. https://doi.org/10.3389/feduc.2020.582882

Camitan, D. S., \& Bajin, L. N. (2021). The importance of well-being on resiliency of Filipino adults during the COVID-19 enhanced community quarantine: A necessary Condition Analysis. Frontiers in Psychology, 12. https://doi.org/10.3389/fpsyg.2021.558930 
Platon, J.

Chow, K. M., Tang, W. K., Chan, W. H., Sit, W. H., Choi, K. C., \& Chan, S. (2018). Resilience and well-being of university nursing students in Hong Kong: A cross-sectional study. BMC Medical Education, 18(1). https://doi.org/10.1186/s12909-018-1119-0

Eliüşük, B. A. (2018). Adaptation of the PERMA Well-being scale into Turkish: Validity and reliability studies. Educational Research and Reviews, 13(4), 129-135. https://doi.org/10.5897/err2017.3435

Ford, B. \& Mauss, I. B. (2020). Emotion experience and well-being. In R. Biswas-Diener \& E. Diener (Eds), Noba textbook series: Psychology. Champaign, IL: DEF publishers.

Garcia, R. (2018, August 15). Understanding the Filipino brand of happiness. Medium. https://medium.com/humaling/understanding-the-filipino-brand-of-happiness-a7d74c618f1

Gräbel, B. F. (2017, August). The relationship between wellbeing and academic achievement: A systematic review. https://essay.utwente.n1/73514/

Harms, P. D., Brady, L., Wood, D., \& Silard, A. (2018). Resilience and well-being. In E. Diener, S. Oishi, \& L. Tay (Eds.), Handbook of well-being. Salt Lake City, UT: DEF Publishers.

Harold Cohen, P. D. (2016, May 17). What is resilience? Psych Central. https://psychcentral.com/lib/what-is-resilience\#1

Hurley, K. (2020, December 10). What is resilience? Your guide to facing life's challenges, adversities, and crises. Resilience. https://www.resilience.eu.org/2021/07/what-is-resilience-your-guide-to-facing.html

King-White, D.L. (2019). The role of school counselors in supporting mental health models in schools. Journal of School Counseling, 17(4).

Kajbafnezhad, H., \& Keshi, A. K. (2015). Predicting personality resiliency by psychological well-being and its components in girl students of Islamic Azad University. i-Manager's Journal on Educational Psychology, 8(4), 11-15. https://doi.org/10.26634/jpsy.8.4.3268

Kashdan, T. B. (2017, October 12). How many ways can we measure well-being? Psychology Today. https://www.psychologytoday.com/gb/blog/curious/201710/how-many-ways-can-we-measure-well-bei ng

Krok, D. (2017). When is meaning in life most beneficial to young People? Styles of meaning in life and well-being among late adolescents. Journal of Adult Development, 25(2), 96-106. https://doi.org/10.1007/s10804-017-9280-y

Lanquist, L. (2016, August 11). The power of support systems for people Battling serious illnesses. SELF. https://www.self.com/story/yes-having-a-support-system-really-does-matter-when-youre-battling-a-ter minal-illness

Li, Z.-S., \& Hasson, F. (2020). Resilience, stress, and psychological well-being in nursing students: A systematic review. Nurse Education Today, 90, 104440. https://doi.org/10.1016/j.nedt.2020.104440

Malindog-Uy, A., \& Anna Rosario Malindog-Uy is Professor of Political Science. (2020, July 19). COVID-19 impact on mental health OF FILIPINOS. The ASEAN Post. https://theaseanpost.com/article/covid-19-impact-mental-health-filipinos

McGillivray, C. J., \& Pidgeon, A. M. (2015, February). Resilience attributes among university students: A comparative study of psychological distress, sleep disturbances and mindfulness. https://core.ac.uk/download/pdf/236409719.pdf

Molina-Azorin, J. F. (2016). Mixed methods research: An opportunity to improve our studies and our research skills. European Journal of Management and Business Economics, 25(2), 37-38. https://doi.org/10.1016/j.redeen.2016.05.001

Mulder, P. (2018). PERMA Model. https://www.toolshero.com/psychology/perma-model/

Nelson, M., Tarabochia, D., \& Koltz, R. (2015). PACES: A model of Student Well-being Mark D. Nelson, dawn ... https://files.eric.ed.gov/fulltext/EJ1079029.pdf

Pascha, M. (2020). The PERMA Model: Your Scientific Theory of Happiness. Positive Psychology. https://positivepsychology.com/perma-model/

Pogosyan, M. (2016, November 6). Positive emotions and well-being. Psychology Today. https://www.psychologytoday.com/intl/blog/between-cultures/201611/positive-emotions-and-wellbeing Quadra-Balibay, A. (2020, April 21). Quarantine Survey says Filipinos feel more positive emotions, concern for

62 Consortia Academia Publishing (A partner of Network of Professional Researchers and Educators) 
Explanatory-sequential approach on PERMA and resilience among students of local colleges in Batangas

others tops responses. Good News Pilipinas.

https://www.goodnewspilipinas.com/quarantine-survey-says-filipinos-feel-more-positive-emotions-con cern-for-others-tops-responses/

Southwick, S. M., Sippel, L., Krystal, J., Charney, D., Mayes, L., \& Pietrzak, R. (2016). Why are some individuals more resilient than others: The role of social support. World Psychiatry, 15(1), 77-79.

https://doi.org/10.1002/wps.20282

Spencer, B. (2019, April 25). Supporting student wellbeing in schools [web log]. https://blog.teamsatchel.com/supporting-student-wellbeing-in-schools

Svence, G., \& Majors, M. (2015). Correlation of well-being with resilience and age. http://www.scientiasocialis.lt/ppc/node/files/pdf/45-56.Svence_Vol.9-1_ppc.pdf

Turner, M., Scott-Young, C. M., \& Holdsworth, S. (2017). Promoting wellbeing at university: The role of resilience for students of the built environment. Construction Management and Economics, 35(11-12), 707-718. https://doi.org/10.1080/01446193.2017.1353698

VandenBos, G. R. (2015). APA dictionary of psychology. American Psychological Association. https://doi.org/10.1037/14646-000

Yu, J., \& Chae, S. (2020). The mediating effect of resilience on the relationship between the academic burnout and psychological well-being of medical students. Korean Journal of Medical Education, 32(1), 13-21. https://doi.org/10.3946/kjme.2020.149 
Platon, J.

64 Consortia Academia Publishing (A partner of Network of Professional Researchers and Educators) 